\title{
OS CONGRESSOS BRASILEIROS - PONTES PARA A LIBERDADE E TRANSFORMAÇÃO DA ENFERMAGEM ${ }^{1}$
}

\author{
Maria Itayra Coelho de Souza Padilha \\ Alcione Leite da Silva ${ }^{3}$ \\ Miriam Süsskind Borenstein ${ }^{2}$
}

Padilha MICS, Silva AL, Borenstein MS. Os congressos brasileiros - pontes para a liberdade e transformação da enfermagem. Rev Latino-am Enfermagem 2001 maio; 9(3):7-13.

O estudo trata da compreensão dos pontos de convergências dos Congressos Brasileiros de Enfermagem e a forma como se apresentam na produção do conhecimento em Enfermagem. O método de investigação utilizado é a pesquisa histórica, com análise documental dos Anais dos Congressos Brasileiros de Enfermagem no período de 1977 a 1987. Os principais pontos de convergência presentes nos discursos dos palestrantes referem-se a: educação superior e de nível médio; assistência de enfermagem hospitalar e de saúde pública; políticas de saúde e; a imagem da/o enfermeira/o e suas transformações ao longo dos anos.

UNITERMOS: história da enfermagem, congressos

\section{BRAZILIAN CONGRESSES - BRIDGES TO FREEDOM AND NURSING TRANSFORMATION}

This study concerns the comprehension of the converging points in Brazilian Nursing Congresses as well as of their contribution to the production of nursing knowledge. The investigation method used was that of historical research with a documental analysis of the Proceedings of Brazilian Nursing Congresses from 1977 to 1987. The main converging points appearing in the lecturers' speeches refer to: higher and secondary education; nursing care; healthcare policies; the image of nurses and its transformation over the years.

KEY WORDS: nursing history, congresses

\section{LOS CONGRESOS BRASILEÑOS - PUENTES PARA LA LIBERTAD Y LA TRANSFORMACIÓN DE LA ENFERMERÍA}

El estudio trata sobre la comprensión de los puntos de convergencias en los Congresos Brasileños de Enfermería y la forma como se presentan, contribuyendo para la producción del conocimiento en Enfermería. El método de investigación utilizado fue la pesquisa histórica, con análisis documental de las publicaciones de los Congresos Brasileños de Enfermería en el período de 1977 a 1987. Los principales puntos de convergencia presentes en los discursos de los conferencistas se relacionan con: educación superior y de nivel medio; atención de enfermería clínica y de salud pública; políticas de salud y la imagen de la enfermera/o y sus transformaciones a lo largo de los años.

TÉRMINOS CLAVES: historia de la enfermería, congresos

\footnotetext{
${ }^{1}$ Este trabalho faz parte das atividades desenvolvidas pelo Grupo de Estudos da História do Conhecimento em Enfermagem (GEHCE) do Departamento de Enfermagem da UFSC

'Doutor em Enfermagem, Professor Adjunto; ' ${ }^{3}$ Doutor em Filosofia de Enfermagem, Professor Titular; Departamento de Enfermagem da UFSC. Pesquisadora do $\mathrm{CNPq}$
} 


\section{INTRODUÇÃO}

A história da enfermagem vem construindo seu conhecimento como um processo dinâmico, que tende a nascer da prática e a ela se voltar num movimento de busca de níveis crescentes de qualidade e complexidade. Esse movimento, pontuado por contradições, convergências e decadências, representa a história dos profissionais, dos pensadores da enfermagem e da prática de enfermagem. História que é feita de paixões, de limites e determinações, de interesses e experiências do seu próprio tempo, mas que também reflete o processo educacional de formação dos enfermeiros em determinada época e a forma como a prática profissional se constrói.

0 processo da construção do conhecimento parece que tem tido como uma de suas principais metas situar a enfermagem no contexto da ciência. Compreender como esse conhecimento tem sido construído, como a ciência da enfermagem tem se consubstanciado, é essencial para o desenvolvimento e progresso da profissão no país. Desenvolvimento este que deve ter como preocupação primordial a melhoria da qualidade de vida da sociedade.

Os Congressos Brasileiros de Enfermagem, ao refletirem a situação por que passa a Enfermagem brasileira, vêm se constituindo em instância de construção do conhecimento em Enfermagem. Desde o seu início, em 1947, representam uma possibilidade para a discussão dos rumos desta construção e do exercício da profissão, buscando compreendê-los e transformá-los.

Nesta perspectiva, este estudo tem como OBJETIVO analisar os pontos de convergência, a partir das temáticas discutidas nos Congressos Brasileiros de Enfermagem, no período de 1977 a 1987*. Por convergência entendemos aqueles aspectos que se repetem, com discussões que evoluem de um ano para o outro, apontando soluções, ampliando a discussão ou produzindo um novo conhecimento a ser apreendido e utilizado pela Enfermagem brasileira.

\section{PROCEDIMENTOS METODOLÓGICOS}

Para este estudo, optamos pela investigação histórica, enquanto linha metodológica, através da análise documental do conteúdo dos Anais dos Congressos Brasileiros de Enfermagem**, no período especificado acima. A análise documental permite obter informações, codificá-las e categorizá-las de forma quantitativa ou qualitativa, sendo esta última a de nossa escolha ${ }^{(1)}$. Em um levantamento prévio, realizamos uma leitura exaustiva do conteúdo

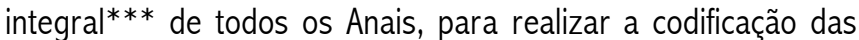
temáticas ou discussões que considerávamos repetidas ao longo dos anos e que apresentavam algum tipo de convergência na abordagem temática. A partir daí, fomos agrupando as temáticas convergentes, das quais emergiram as seguintes categorias: educação superior e de nível médio; assistência de Enfermagem (neste aspecto incluímos a administração de enfermagem); políticas de saúde; imagem do enfermeiro, as quais apresentamos, a seguir.

\section{COMPREENSÃO DAS CONVERGÊNCIAS}

Vale ressaltar que na maioria dos congressos as Comissões Organizadoras das temáticas a serem abordadas como Temas Centrais preocupavam-se em estabelecer discussões acerca dos pontos acima citados, ou seja, Educação Superior, Assistência de Enfermagem nas instituições de saúde, Política de Saúde e a Imagem do Enfermeiro vigente à época do congresso.

Em cada congresso percebe-se uma confluência dos temas para a situação em que se encontra o país, o que é bastante positivo, já que acompanha as transformações por que passa o sistema de saúde, educacional e de política brasileira.

Por outro lado, quando se considera que no período em estudo o Brasil passava por inúmeras transformações em todos os sentidos, percebe-se que a enfermagem procura arduamente acompanhar estas transformações, em detrimento algumas vezes, das suas próprias necessidades enquanto profissão para atender a política governamental de saúde e educação.

\section{Ensino superior e de nível médio}

0 congresso de 1977 marca um momento decisivo na discussão sobre os rumos do ensino superior, levando em conta principalmente as exigências do Parecer $163 / 72$ no que se refere a importância da Licenciatura nos Cursos de Enfermagem, objetivando formar Enfermeiras para o ensino de profissionais de nível médio (auxiliares e técnicos de enfermagem), considerando a Lei n 5692/

\footnotetext{
* 0 recorte histórico se deu devido a vinculação do estudo ao projeto de pesquisa intitulado "Os caminhos da construção do conhecimento da enfermagem brasileira no período de 1977-1987" desenvolvido pelo GEHCE (Grupo de Estudos da História do Conhecimento da Enfermagem do Departamento de Enfermagem da UFSC), a partir da análise dos Anais dos Congressos Brasileiros de Enfermagem

** Não foram incluídos nesta análise os Anais de 1984 e 1986, por não terem sido encontrados

*** Os Anais estudados contém os discursos oficiais das presidentes da ABEn nacional e regional, além das palestras proferidas nos Temas oficiais dos CBENs e o relatório final do CBEN
} 
71, que tratou da regulamentação das habilitações profissionalizantes. A temática indicava novos caminhos para a construção do conhecimento em Enfermagem, através da abertura de novos campos de trabalho. No que se refere ao ensino, constatamos o incentivo do aumento de vagas e a abertura de novos cursos de Enfermagem (passando de 41 a 57 o número de cursos de Enfermagem no país, no período de 1976 a 1978); o incentivo à criação de cursos de Pós-Graduação (5 escolas empenhavam-se em cursos de mestrado, 197 docentes freqüentavam cursos de mestrado e 6 de doutorado ${ }^{(2)}$. Vale considerar inclusive o grande impacto social ocorrido a partir deste incremento na formação de profissionais de enfermagem e sua inserção no mercado de trabalho tão carente desse profissional e tão largamente discutido em todos os congressos.

Esta discussão continua mostrando a sua importância nos congressos seguintes e é ampliada pelas implicações para a enfermagem na instituição do Sistema Nacional de Saúde criado pela Lei $n^{0} 6229 / 75$, no que concerne às atividades desenvolvidas ou não pelas/os enfermeiras/os nos novos órgãos criados (Ministério da Saúde, Ministério da Previdência Social, Ministério da Educação e Cultura, Ministério do Trabalho, Secretarias Estaduais de Saúde) e Serviços particulares, procurando especificar a situação de Enfermagem nestes sub-sistemas.

$\mathrm{Na}$ busca de alternativas para a ampliação, melhoria e novas tecnologias para que o Ensino Superior pudesse acompanhar as transformações políticas, percebemos nos congressos uma grande afluência de projetos criativos e inovadores no ensino superior. Há um traçado de convergências nos assuntos que permitam entrelaçar e compreender melhor a relação entre educação e trabalho e entre ensino e serviços de saúde.

Em 1979, é apresentado o "Projeto Vitória" da Universidade Federal de Pernambuco, visando desenvolver um modelo de assistência a saúde com a real participação comunitária e de ensino voltado para os cuidados primários de saúde. No mesmo ano a Universidade Federal do Ceará, apresenta uma estratégia para a obtenção efetiva da integração docente assistencial (IDA), utilizando estudantes de Enfermagem como mecanismo para a efetivação deste processo, atendendo ao programa de educação para a saúde e ao plano de extensão de cobertura preconizado pelo PIASS (Decreto Lei $n^{0}$ 78307/76). A Universidade Federal da Bahia também divulgou no mesmo ano experiência semelhante. A Universidade Federal da Paraíba apresentou a sua experiência com a realização das habilitações, vigentes pelo Parecer 163/72, em forma de internato, como uma maneira de integrar mais ainda a escola aos serviços de saúde.

Outra grande novidade divulgada neste congresso foi a experiência da Universidade Federal do Rio de Janeiro - Escola de Enfermagem Anna Nery, sobre o projeto de mudança curricular no ensino de graduação em Enfermagem, o qual tinha como linha mestra a idéia de integração teoria-prática e a inclusão da pesquisa como parte da construção curricular. Este projeto mostra a integração da Enfermagem em projetos em nível central (Projeto de Integração Curricular), como parte do projeto Novas Metodologias, desenvolvido pelo MEC. Tanto assim, que o novo currículo da Escola de Enfermagem Anna Nery foi denominado Currículo Novas Metodologias.

As experiências apresentadas evidenciaram as reformulações curriculares por que passava o ensino de enfermagem. Reformulações estas, calcadas no ensino ministrado em graus de complexidade diferentes e girando em torno da regionalização dos serviços de saúde dos estados.

Neste congresso os enfermeiros são chamados a refletir sobre que tipo de modificação no ensino poderia repercutir sobre a prática, transformando-a. De todos os Anais de Congressos analisados, este foi o que abordou a temática do Ensino Superior de Enfermagem com maior abrangência e profundidade e maior relação com os novos projetos de modificação do sistema de saúde.

Nos demais congressos percebemos que a preocupação com o ensino superior é um assunto sempre presente nas pautas de discussão, mas de forma a chamar os enfermeiros a refletir sobre os currículos de suas escolas, de forma a torná-los cada vez mais próximos das necessidades dos campos de prática e da realidade brasileira, atendendo as necessidades sociais, principalmente àquelas referentes a assistência primária de saúde. Estava presente, nos esforços de convergências, a amplitude do significado social do que se abordava nos congressos, pela preocupação com as propostas governamentais de saúde, pedindo uma redefinição de um posicionamento dos profissionais de Enfermagem frente a realidade que se apresentava nas exigências de um novo sistema de saúde, regionalizado e hierarquizado, visando a universalidade das ações de saúde.

0 ensino de nível médio, por sua vez, caminhava a reboque das discussões sobre o ensino superior, enfatizado pelas políticas de saúde vigentes que incentivam a sua formação e continuidade, principalmente do atendente de Enfermagem, acrescido esse contingente pelo Agente Comunitário de Saúde; elemento sem profissionalização, considerado por todos como um dos grandes entraves na melhoria da qualidade da assistência de Enfermagem prestada.

Este fato levou a ocorrência de inúmeros projetos de capacitação de pessoal auxiliar de Enfermagem em todo o Brasil, não tendo obtido até os dias de hoje a devida resolução do problema. No período em estudo constata-se também a expansão dos cursos de técnico de Enfermagem (57 para 174) e de auxiliares de Enfermagem (90 para 129), entre 1976 a 1987; habilitação de técnico e auxiliar de Enfermagem ao nível de ensino de $2^{\circ}$ grau 
(resoluções 07/77 e 08/77); e a inclusão obrigatória de "Programas de Saúde" nos currículos plenos dos estabelecimentos de $1^{\circ}$ e $2^{\circ}$ graus (Lei 5.692/71).

Embora seja um problema extremamente grave, a temática foi discutida em todos os congressos da década analisada, porém sem a abrangência que merecia, obtendo maior destaque apenas no congresso de 1982 e 1987, que discutiu basicamente, recursos humanos, mercado e condições de trabalho na Enfermagem, incluindo todos os elementos da equipe de Enfermagem.

0 ensino de pós-graduação em Enfermagem e, por conseqüência, a pesquisa científica não pode ser considerado como uma convergência na pauta das discussões porque não foi um tema constante, não se percebendo a ênfase na construção do conhecimento a partir da mesma. Na verdade, é incluído como um dos sub-temas centrais apenas no congresso de 1979 como parte do assunto "Preparo e aperfeiçoamento de recursos humanos para a Enfermagem", em que a autora coloca a preocupação com os rumos da Enfermagem, enquanto profissão, e diz da necessidade de estudos que conduzam a identificação profissional e formulação de um corpo de conhecimentos científicos que prescrevam "a prática no que se refere a contribuição da profissão à sociedade" ${ }^{\text {(3) }}$. Esta importância é reforçada novamente no congresso de 1981, em Sessão Especial do congresso sobre a "Enfermagem e a Pesquisa", quando é enfocada a importância da pesquisa científica e tecnológica para a evolução de qualquer profissão. Há uma critica aos profissionais que "realizam pesquisas apenas para a obtenção de titulação" (4) chamando a atenção para o desenvolvimento de pesquisas que tratem de análises de casos populacionais que enfatizem o compromisso social da Enfermagem com a saúde coletiva.

Nos demais congressos nacionais, a presença da pesquisa pode ser percebida nas exposições, as quais se baseiam em pesquisa científica, e também no oferecimento pela ABEn de prêmios pelos melhores trabalhos apresentados nos eventos. De certa forma, ai está a convergência e o estímulo a pesquisa em enfermagem.

A não abordagem da Pesquisa na Enfermagem talvez não tenha adquirido maior ênfase devido a organização dos Seminários Nacionais de Pesquisa em Enfermagem (SENPE), também promovidos pela ABEn a partir de 1979. Além disso, este vazio percebido acerca de temáticas envolvendo a pós-graduação e a pesquisa em Enfermagem, talvez se deva aos Comitês de PósGraduação, realizados a cada congresso para discutir os rumos a serem seguidos pela mesma.

\section{Assistência de enfermagem}

Outro assunto que tomou grande parte da preocupação das comissões organizadoras dos congressos de enfermagem foi a assistência de enfermagem. Podemos dizer que foi a menina dos olhos de todos os expositores, tendo como referência a construção da prática de Enfermagem, com vistas a melhoria do cuidado de Enfermagem prestado ao cliente, seja no âmbito hospitalar ou comunitário.

A situação da Enfermagem brasileira nos serviços de saúde do país se constituiu em marco de convergência para compreendêla, refletir sobre ela, propor novos modelos assistenciais a serem utilizados e/ou divulgar modelos já utilizados nas instituições de saúde.

As lutas dos enfermeiros para garantir o espaço da Enfermagem nas instituições de saúde se manifestam em todas as falas, principalmente relativas a sub-utilização deste profissional ou então ao total desvio para as funções administrativas em detrimento do cuidado direto de Enfermagem. Na verdade, o cuidado direto é pouco discutido como parte do papel do enfermeiro, considerandoo como mais próprio dos profissionais subalternos, como o auxiliar de Enfermagem e o técnico de Enfermagem, havendo também uma crítica ferrenha às instituições privadas que, durante todo o período estudado, ainda contratavam atendentes de Enfermagem para este fim.

Esta percepção sobre o cuidado de enfermagem refletia a realidade da prática, isto é, o cuidado de Enfermagem era compreendido apenas como aquele realizado diretamente com 0 cliente e confundido com a execução de técnicas de Enfermagem, portanto delegáveis. A visão de cuidado de Enfermagem de uma forma mais ampla, globalizada e não apenas este cuidado direto seria reintegrada, posteriormente, no final da década de oitenta, já havendo um prenúncio disto no congresso de 1987.

0 congresso de 1978 que é considerado um grande marco para as reflexões acerca da Enfermagem conta com debatedores interessados em divulgar novas metodologias assistenciais, tais como, a Metodologia do Diagnóstico de Saúde em Santa Catarina, que, atendendo a política governamental de saúde regionalizada e de zoneamento assistencial, integrava com isso o ensino e assistência de Enfermagem em nível estadual. No mesmo congresso, a Universidade Federal da Bahia também apresentou uma experiência de ensino com o plano de extensão de cobertura, visando interiorizar as ações simplificadas de saúde.

0 congresso de 1979 e os demais mantém a tônica do congresso anterior com a preocupação em discutir os "desafios da Enfermagem brasileira", a partir de tantas propostas surgidas no congresso anterior e visando clarear a inserção da Enfermagem na sociedade e no mercado de trabalho, bem como compreender a prática de Enfermagem e a formação de enfermeiros em nível de graduação e pós-graduação, desenvolvidos no país. Mas enfim, que desafios são estes? E que convergências apresentam com os congressos posteriores?

As reflexões indicam uma grande preocupação com 0 
quantitativo do pessoal de enfermagem, introduzindo a questão de que um dos grandes problemas seria a discrepância existente entre o número de enfermeiras com relação aos demais membros da equipe de enfermagem. Há uma forte tendência em que os enfermeiros assumam as funções administrativas, principalmente àquelas vinculadas aos cargos de chefias de serviço e de unidades de internação para garantir a sua função de liderança da equipe de Enfermagem. Esta vertente de discussão começa a se modificar no congresso de 1987, quando se começa a compreender e discutir o processo de trabalho, de cada membro da equipe de saúde, e entende-se que o enfermeiro é responsável pela administração da assistência de Enfermagem, o que implica em um retorno ao cuidado de Enfermagem como parte precípua de seu papel enquanto enfermeiro.

Percebemos que, a partir de 1978 os enfermeiros começam a questionar com mais veemência acerca da sua atuação nos serviços de saúde, bem como sobre a forma como os clientes e suas doenças são compreendidas pela equipe de saúde. Dandose esta de forma individual, curativa, centrada em tarefas e não na globalidade do indivíduo. Emergem, assim, propostas de modelos assistenciais e administrativos diferenciados e mais críticos, com abordagens teóricas na atuação prática.

A década de oitenta deflagra grandes transformações na área da saúde que irão influir profundamente na revisão dos currículos de Enfermagem e do cuidado de Enfermagem nos serviços de saúde hospitalar e comunitário, a despeito do ocorrido com a proposta curricular elaborada pela Comissão de Especialistas de Enfermagem MEC/DAU e recusada pela comunidade de enfermagem representada na reunião especial em Salvador/Bahia. As Ações Integradas de Saúde (AIS), assim denominadas a partir de 1983, incentivavam esse processo de mudanças dentro da proposta de reordenação dos serviços públicos e, além disso, proporcionavam base técnica e princípios estratégicos para a reforma sanitária.

A prioridade na atenção primária e o lema "saúde para todos no ano 2000" agitaram os meios acadêmicos e serviços, gerando a construção de propostas de transformações curriculares, que privilegiassem esta grande conquista na formação de enfermeiros generalistas e voltados para a saúde coletiva.

Esta nova compreensão da prática de Enfermagem vai se refletir nos serviços de saúde, nos currículos das escolas, principalmente a partir da metade da década de oitenta, e continua em fase de transformação e ruptura dos velhos paradigmas até os dias de hoje.

\section{Políticas de saúde}

Outro aspecto constante na pauta de discussão de todos os congressos é a política de saúde vigente e suas conseqüências para a Enfermagem. Há uma preocupação sistemática na melhor forma como a Enfermagem irá se inserir nos programas de saúde, seja nos níveis dirigentes, seja como executora das medidas, seja como prejudicada pelas mesmas.

É clara a intenção das organizadoras dos congressos em informar a comunidade de Enfermagem sobre as políticas de saúde no convite a profissionais especialistas em diferentes áreas para discussão sobre o tema.

Percebemos porém que, a partir de 1979, a Enfermagem e os enfermeiros, em especial, são chamados a questionar e refletir sobre o que nos era imposto pelo governo em termos de política de saúde e educação, perguntando principalmente: quem somos? 0 que queremos? Por que temos que nos subjugar às decisões superiores? 0 grande ressentimento dos enfermeiros era a não participação nos processos decisórios da área de saúde o que implicou muitas vezes na sua não inclusão nos Programas de Saúde, ficando na verdade correndo atrás do tempo e da história para acompanhar o processo e reclamar da sua não participação.

Os congressos de enfermagem se agitavam com a discussão de conseguir melhores condições de trabalho para a Enfermagem e com a adequação dos currículos às novas políticas de saúde.

Acreditamos que deste momento em diante, com a emergência de um novo movimento político na ABEn, o chamado participação, que se concretizará em 1984 no congresso de Belo Horizonte, os enfermeiros são chamados a "olhar para fora de si, sair da clausura, buscar uma nova maneira de pensar, e principalmente, questionar sempre" em busca de novas soluções para problemas antigos.

Implementada pelo novo movimento, é aprovada a nova Lei do Exercício Profissional de Enfermagem em 1986 (Lei n 7498/ 86) e iniciada a discussão para a elaboração de um Novo Currículo Mínimo de Enfermagem, que seria aprovado posteriormente em $1994^{(5)}$. A inserção da Enfermagem frente a reforma sanitária brasileira como pauta de vários congressos em 1987 já era uma realidade, considerando a importância que foi dada a mesma na $8^{a}$ Conferência Nacional de Saúde, que representou um marco na direção do novo Sistema Nacional de Saúde, legitimando a saúde como direito dos indivíduos e dever do Estado e propôs as bases para a reformulação do Sistema Nacional de Saúde - mediante uma ampla Reforma Sanitária tendo as Ações Integradas de Saúde como principal instrumento estratégico. Aliado a isto, podemos detectar a formação da Assembléia Constituinte com propostas do conteúdo de saúde para a Nova Constituição Brasileira, que garantiriam os rumos de uma política de saúde igualitária, universalizante e que permitisse 0 acesso de toda população aos serviços de saúde de forma regionalizada.

$039^{\circ}$ CBEn, em 1987, ocorre exatamente em meio às mais acirradas discussões acerca da Reforma Sanitária Brasileira e 
lutas da Comissão Nacional de Reforma com a participação de enfermeiros, junto a Assembléia Nacional Constituinte para garantir que: "a saúde seja entendida como um processo resultante de condições de vida e a atenção à saúde não se restrinja à assistência médica, mas a todas as ações de promoção, proteção e recuperação; seja um direito de todos e um dever do Estado, assegurados constitucionalmente, daí decorrendo a natureza social das ações e serviços de saúde, subordinados ao interesse público; o setor saúde seja reorganizado e redimensionado, de forma a permitir o acesso universal e igualitário de toda a população a todas as ações e serviços necessários, dentro do conhecimento e da tecnologia disponíveis" ${ }^{\prime \prime 6)}$.

É colocado em debate o grande desafio enfrentado por toda a equipe de saúde e pela população em geral - a assistência prestada, o que significa rever a atual organização dos serviços em função da redefinição do modelo de assistência tendo por referência as necessidades da população. A Enfermagem não pode se alijar deste processo e seu engajamento deve ser integral para não correr o risco de receber o "pacote" pronto e submeter-se sem questionar ${ }^{(6)}$.

\section{Imagem da enfermeira}

A imagem da enfermeira é outro aspecto largamente discutido e cantado em prosa e verso em todos os congressos. Embora ainda não resolvido pelas/os enfermeiras/os e, portanto, não se constituindo em um aspecto de convergência, pela sua resolução ou pela produção de conhecimento decorrente de sua discussão, optamos por enquadrá-lo pela amplitude de sua ênfase.

A imagem da enfermeira, aqui enfatizando o gênero feminino, é compreendida de várias formas, no período de análise. Em alguns momentos é reforçada aquela de caridade, amor ao próximo e o seu caráter de submissão construído historicamente como influenciando a não valorização da mesma pela sociedade, influindo numa visão onírica da enfermeira como um "anjo branco", "anjo do bem", "anjos de candura" e "anjos tutelares de médicos". Em nenhum dos congressos investigados percebemos a discussão do inverso desta visão tão cândida da profissão, isto é, da "prostituta", "anjo negro", "empregada de médico".

Verificamos que no final da década de 70 e mais especificamente no congresso de 1979, as enfermeiras são chamadas a modificar a sua imagem diante da sociedade e da equipe de saúde, mostrando que a mesma desempenha um papel de parceira no processo de cuidado, não uma mera executora de ordens médicas. É a substituição da imagem de "carinhosa, pela competência técnica e coerente com a realidade vivida pela nossa sociedade".

0 fato da Enfermagem ser uma profissão notadamente feminina foi outro aspecto da imagem da enfermeira questionado e analisado do ponto de vista das várias profissões femininas, que na sociedade patriarcal são menos valorizadas que as profissões masculinas. Há uma compreensão por parte das expositoras que é impossível "analisar a constituição da enfermagem moderna brasileira, ignorando estas características, para assim compreender o processo de discriminação salarial e de valor de trabalho profissional" ${ }^{(7)}$.

0 congresso de 1979 é particularmente rico em encaminhar estas questões optando inclusive por incluir como um dos sub-temas centrais com o título "questões e mitos acerca de modelos de assistência de enfermagem", no qual a autora discute de forma ampliada alguns mitos como "o trabalho dos enfermeiros é menos intelectual que manual; e enfermagem é definida quanto ao que ela é e o que não é; os enfermeiros preferem administrar que cuidar, dentre outros"(8).

É importante compreender que existem duas imagens a serem discutidas e refletidas para a construção do conhecimento em Enfermagem. A imagem que a sociedade tem da enfermeira e da enfermagem é aquela que a própria enfermeira e a enfermagem tem de si mesma. Neste sentido, a imagem da sociedade é aquela que percebe a enfermeira e os demais membros da equipe como enfermeiras, não fazendo diferenciação dos papéis desempenhados. 0 congresso de 1983 é um exemplo disto.

Nos demais congressos, embora a temática não tenha sido abordada isoladamente, foi nitidamente incluída indiretamente nas temáticas, ampliando os aspectos anteriores e apontando para transformações na imagem da enfermeira, a partir de sua formação universitária e de sua posição em postos de comando nas instituições de saúde e governamentais.

Acreditamos que a temática não obteve a convergência esperada até 1987, porque na ocasião ao discutir-se mercado de trabalho, condições de trabalho e piso salarial, a discussão era de que a Enfermagem ainda era uma profissão "marginal na sociedade e ocupa um lugar secundário na família e no trabalho. 0 status de inferioridade da mulher em todos os níveis da sociedade é mantido e aprofundado pelas classes dominantes através da educação familiar, da escola, dos meios de comunicação de massa, das religiões e da legislação"(6).

Esta desigualdade não é necessariamente de direitos femininos e masculinos, mas sim, um direito hierarquizado socialmente na organização das profissões. A autora finalizou sua fala enfatizando a importância de se construir um projeto coletivo de Enfermagem que viabilizasse caminhos para a resolução dos problemas que enfrentávamos no cotidiano da Enfermagem, e que fizessem com que a luta por uma profissão mais valorizada socialmente ganhasse mais força e espaço de discussão, principalmente se partissem da categoria como entidade organizativa de um conjunto e não de grupos isolados. 
CONSIDERAÇÕES FINAIS

Neste estudo, buscamos analisar os aspectos de convergência na construção do conhecimento nos Congressos Brasileiros de Enfermagem, na década de 1977 a 1987. Neste sentido, verificamos que este período foi rico em discussões e encaminhamentos acerca de questões relativas ao Ensino, Assistência, Pesquisa, Políticas de Saúde e imagem profissional.

Estas grandes temáticas, que permearam as discussões na quase totalidade dos discursos das/os conferencistas, demonstram a preocupação com o futuro da Enfermagem, suas lutas e conquistas ao longo dos anos, relacionando-as com os movimentos sociais, políticos e econômicos, além de manter em constante ebulição a crítica sobre como estávamos conduzindo a nossa prática cotidiana.

Ao retratar os limites e, ao mesmo tempo, as possibilidades e a abrangência da ação profissional, os Congressos Brasileiros de Enfermagem, desta década, apontaram novos caminhos para a construção do conhecimento em enfermagem, os quais se consubstanciariam em novos paradigmas para a profissão, no sentido de torná-la mais crítica, participativa e comprometida com as questões sociais, políticas e econômicas, que determinam as políticas de educação e saúde.

Nesta perspectiva, os Congressos Brasileiros de Enfermagem, da década de 1977 a 1987, refletiram a construção

\section{REFERÊNCIAS BIBLIOGRÁFICAS}

1. Holloway I, Wheeler S. Qualitative research for nurses, 1996. 120.

2. Matos AV. A Enfermagem e o sistema nacional de saúde. Anais do $30^{\circ}$ Congresso Brasileiro de Enfermagem, Belém; 1978; p.13-30; Belém-PA; 1978.

3. Rhodus CC. Preparo e aperfeiçoamento de recursos humanos para a enfermagem. Anais do $31^{\circ}$ Congresso Brasileiro de Enfermagem; 1979. Fortaleza, Ceará. p. 93-100.

4. Machado PA. A enfermagem e a pesquisa. Anais. do $33^{\circ}$ Congresso Brasileiro de Enfermagem; 1981. Manaus, Amazonas. p. 113-8.

5. Associação Brasileira de Enfermagem (ABEn). Caderno de Legislação/Documentos I. A nova lei do exercício profissional da enfermagem. Comissão de Legislação. Brasília - DF: 1987.

6. Silva J. A inserção de enfermagem frente à reforma sanitária brasileira. Anais do $39^{\circ}$ Congresso Brasileiro de Enfermagem; 1987; Salvador, Bahia. p. 51-6. da história da Enfermagem brasileira da época, realizada por gerações de enfermeiras e enfermeiros, com vistas a impulsionar a reflexão crítica dos problemas da profissão e investir na produção de conhecimentos, direcionados para a crescente complexidade e qualidade da prática profissional.

As categorias e sub-categorias apontadas, enquanto convergências no processo de construção do conhecimento de Enfermagem, continuam a permear os discursos da Enfermagem o que reflete o processo dinâmico e político no avanço deste conhecimento. Evidencia também que as transformações no contexto da Enfermagem estão diretamente relacionadas às transformaç̃es mais globais, ou seja, à estrutura sócio-econômica-política do sistema como um todo. Deste modo, as convergências evidenciam o movimento histórico da categoria, na busca de níveis crescentes de complexidade de consciência política, a qual não pode ser descontextualizada da qualidade das práticas de saúde como um todo e da qualidade de vida da população brasileira.

Finalizando diríamos que os Congressos Brasileiros de enfermagem acompanharam e lançaram novos paradigmas para a profissão, permitindo ao longo do tempo, que esta se tornasse mais crítica e socialmente mais participativa e finalmente uma profissão comprometida efetivamente com a saúde da população e não mais simplesmente executora de políticas de saúde.

7. Silva GB. Desenvolvimento da enfermagem - correlação dos problemas da profissão e da mulher na sociedade. Anais do $31^{\circ}$ Congresso Brasileiro de Enfermagem; 1979. Fortaleza, Ceará. p. 27-32.

8. Paim L. Questões e mitos acerca de modelos de assistência de enfermagem. Anais do $31^{\circ}$ Congresso Brasileiro de Enfermagem; 1979. Fortaleza, Ceará. p. 61-70.

\section{Outros Anais dos Congressos Brasileiros de Enfermagem consultados}

Associação Brasileira de Enfermagem - ABEn - DF. Anais. do $32^{\circ}$ Congresso Brasileiro de Enfermagem. Brasília - DF; 01 a 07 de junho de 1980.

Associação Brasileira de Enfermagem - ABEn - RS. Anais. do $34^{\circ}$ Congresso Brasileiro de Enfermagem. Porto Alegre - RS; 24 a 29 de outubro de 1982.

Associação Brasileira de Enfermagem - ABEn - SP. Anais. do $35^{\circ}$ Congresso Brasileiro de Enfermagem. São Paulo - SP; 24 a 30 de setembro de 1983.

Associação Brasileira de Enfermagem - ABEn - PE. Anais. do $37^{\circ}$ Congresso Brasileiro de Enfermagem. Olinda - Recife- PE; 17 a 22 de novembro de 1985. 